\title{
Innovative PLM-based approach for collaborative design between OEM and suppliers: Case study of aeronautic industry
}

\author{
Farouk Belkadi ${ }^{1}$, Nadège Troussier ${ }^{1}$, Frederic Huet ${ }^{1}$, Thierry Gidel $^{1}$, \\ Eric Bonjour ${ }^{2}$, and Benoît Eynard ${ }^{1}$ \\ ${ }^{1}$ Université de Technologie de Compiègne, Centre Pierre Guillaumat \\ BP 60319, rue du Docteur Chweitzer, 60203 Compiègne Cedex, France \\ \{fbelkadi; nadege.troussier; frederic.huet; thierry.gidel; benoit.eynard\}@utc.fr \\ ${ }^{2}$ Université de Franche Comté, Institut FEMTO-ST - UMR CNRS 6174 24, rue \\ Alain Savary, 25000 Besançon, France, ebonjour@ens2m.fr
}

\begin{abstract}
To achieve different assembly operations on the aircraft structure, the aeronautic OEM needs to create and manage various fixture tools. To cope with these needs, the OEM begun to adopt the supplier integration into the tooling development process. This paper presents a conceptual PLM-based approach to support new business partnership of different suppliers. The new business partnership aims to improve the role of supplier in the different tasks of design, configuration and fabrication of the tooling. The use of the PLM concepts is proposed to enhance the collaboration between OEM and the equipment's suppliers. UML models are proposed to specify the structure of the PLM solution. These models describe the relation between the aircraft assembly project, and the tooling design process.
\end{abstract}

Keywords: Suppliers Integration, PLM, UML, Innovative Organisation

\section{Introduction}

The role of supplier in a successful assembly process of aircraft component is very important. Because of the specific aircraft structure, assembly department needs to constantly design new fixture tools used for new assembly operations. It obviously happens when the aeronautic OEM creates new aircraft model, and also when this OEM modifies the existing models to satisfy a particular customer requirement.

To deal with assembly tool costs and time to market optimization challenges, the collaboration between OEM and suppliers should rather go into strategic part-

Please use the following format when citing this chapter:

Belkadi, F., Troussier, N., Huet, F., Gidel, T., Bonjour, E. and Eynard, B., 2008, in IFIP International Federation for Information Processing, Volume 277; Computer-Aided Innovation (CAI); Gaetano Cascini; (Boston: Springer), pp. $157-168$. 
nership, covering the whole tool's lifecycle. The purpose of our research is to develop a new business partnership that enables efficient collaboration between OEM and suppliers. This partnership would enhance the suppliers' role in the design process of assembly tools. The case study concerns the tooling design activities and manufacturing process in the aeronautic industry. The construction of this business partnership is obtained according the following perspectives:

- Definition of its mission and organization,

- Identification of new methodologies to optimize it's operating processes,

- Realization of a collaborative IT framework to support its activities.

The paper focuses on the last perspective and describes a conceptual framework to specify an innovative PLM-based approach. The originality of our approach comes from the high abstraction level of the proposed models based on the situation concept. These concepts are useful to describe different organization forms. It mainly provides specification of IT system that can gives innovation aided by enhancing the project organization in the context of extended enterprise and by favouring interoperability between heterogeneous information shared between OEM and supplier systems (for instance, between SAP system to capture Aircraft information at the OEM level and DELMIA system to identify the tooling behaviour in the assembly process, at the supplier level).

First, we present an overview of the context study and the interest of PLM approach to solve this problematic. Second, a literature review is presented concerning the use of PLM methodologies to support the OEM supplier partnership. Third, we develop our conceptual models of the IT structure. The specification of the PLM-based approach is defined according to a unified modelling that describes, at the same abstraction level, the product (assembly tools or equipment) data and process data. Fourth, the concept of project view is presented. Using the UML activity diagram, we detailed some functionalities of the future collaborative system to manage the equipment design project.

\section{Context and aims of the study}

Traditionally, in the aeronautic industry, the tooling supplier is a basic manufacturer of the assembly tools. The design and manufacture processes of these tools are considered as a sequential one. First the design department delivers the engineering documents of the different aircraft parts; the production engineering department specifies and designs the detailed assembly processes and needed tools to carry out the assembly operations. Then, the production engineering department sends the detailed specifications to the supplier for tools manufacturing.

Figure 1 shows this configuration. On the one hand, three departments are engaged in the global process of assembly tools purchasing: production service specifies the assembly needs, the equipment's R\&D designs the tooling structure and the purchase service negotiates and sends the order to supplier. On the other hand, several suppliers located in different geographical locations are contracted 
with to produce the various parts of the tool. After the completion of the tool, it is sent directly to the production shop for use.

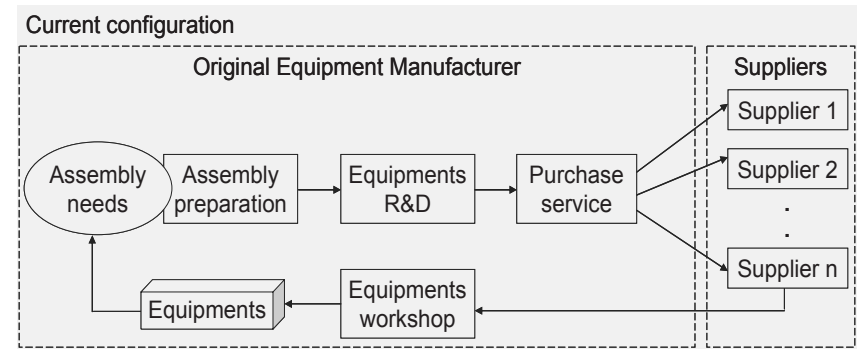

Figure 1 The current OEM-Supplier partnership.

During the manufacturing process of the assembly tool, some modifications may occur on the initial configuration of aircraft components. These modifications imply changes on the specification of the assembly process and thus of the assembly tool. The whole cycle of the assembly tool ordering is then repeated to cope with the new specifications.

This approach proved its limits in the current context. The supplier is not integrated in the first stages of the tools specification and likewise, the OEM has not access to the manufacture process of the tool. Thus, much iteration is occurred before obtaining the final tool definition fulfilling the requirements of production engineering department. Several problems have been observed during the preliminary study: Important time and costs of the assembly tools manufacturing (and consequently for the assembly process of the aircraft parts, delivery date not respected); difficulty to manage the assembly tool range by the OEM (no-use of standards, bad maintenance...); the OEM has to manage several product data interfaces with various partners.

In the future configuration, an innovative PLM-based approach is proposed to support a new business partnership approach. PLM is used for the seamlessly integration of all the information specified throughout all phases of the equipment's life cycle to everyone in the new organization (OEM and a new global supplier network) at every managerial and technical level. Figure 2 shows the proposed configuration of the new business partnership. In this configuration, design tasks', configuration and fabrication of the assembly tool are performed collaboratively with the new global supplier network. Suppliers are already informed by new modifications of the assembly operations and design themselves the new tool.

This description shows important evolutions in the configuration of the development process that can be summarized by considering the shift from a linear and sequential process to a much more "interactionnist" one [1]. This reconfiguration should lead to significant improvement in cost and time saving in association with a greater innovative potential [2], [3]. 
But, what is at stake in this study goes beyond the development process and the impact or the evolution has to be considered at the (inter)organizational level. We can both consider the renewal of the expected shared competences and new governance modalities for these new relationships [4], [5].

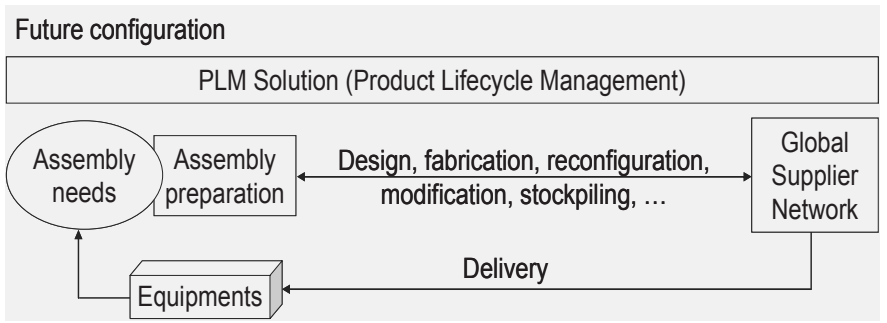

Figure 2 Future configuration of OEM-Supplier partnership.

First, in the traditional development process, the supplier's competences were exclusively manufacturing ones. In the new process, the expected incomes evolve towards innovation capacity, sub-system integration, proactive behavior during the process... This leads to consider the new role of the suppliers, not only as an efficient manufacturer, but more as a service supplier, collaborating in the definition and conception stages [6]. Thus, knowledge transfer and learning capacities are at the core of these new activities for these suppliers [7]. So, as we can see, this evolution will have to be encompassed in a wider evolution of the competences that is expected from the suppliers.

Second, to promote greater innovative potential, interactions between the different partners will have to be carefully managed, because of the change in the nature of their transactions. We can at least anticipate three significant modifications in their relationships. The advantage of the new process is a more important distribution of risk between the partners, previously only assumed by the OEM. In the new context, risk is distributed between all the involved actors. This collaborative organization implies that the partners reveal some of their competences, to combine and fertilize them. Thus, the management of core competences and the equilibrium between the individual interests of each actor and the collective objectives has to be questioned [8], [9]. And, to promote innovation, upstream monitoring and planning will necessarily have to be adapted, in order to facilitate the emergence of new opportunities, which were not anticipated at the beginning of the collaboration. This seems all the more important, that previous studies have shown that innovation through cooperation is linked to a sort of "plasticity" of the relationship, allowing to discover new opportunities and sources of learning [10].

These different preliminary elements shed light on the extended impact of this evolution in the development process, both in the vertical interactions (between OEM and suppliers) and in the horizontal ones (between suppliers). The innovation and collaboration objectives show that governance will have to rely on a new equilibrium between contractual prescriptions and trust based relationships [11]. 
Indeed, to promote innovation, contracts will necessarily remain uncomplete and could lead to strong inertia during the collaboration, while trust, both on competence and behavior, will bring more flexibility in front of novelty and knowledge mutualisation. This vertical and horizontal integration that necessitate risks and benefits sharing, implies developing common practices and methodologies. By sharing project management approach, problem solving methods or design methodology, the partners would in turn shared objectives and decision processes.

Even if this contribution is focused on the definition of a PLM platform, these different elements have to be mentioned. They necessarily won't be neutral for the definition and appropriation of this new support by the different partners.

PLM is used for the seamlessly integration of all the information specified throughout all phases of the equipment's life cycle to everyone in the new organization (OEM and a new global supplier network) at every managerial and technical level. The following section presents a literature review about PLM concept.

\section{About Product Life Management}

PLM is defined as a systematic concept for the integrated management of all product related information and processes through the entire lifecycle, from the initial idea to end-of-life [12]. In [13], PLM is considered as a strategic business approach that applies a consistent set of business solution in support of the collaborative creation, management, dissemination, and use of product information across the extended enterprise.

Such as in the automotive industry, the aeronautic industry is seen to adopt the supplier integration into the development process. The new management culture considers necessary the PLM approach to get these goals [14]. Tang [15] present a literature review of PLM approaches used in automotive industry to improve collaboration between OEM and suppliers. The lifecycle currently support the OEM supplier partnership can be grouped in collaborative environment with three main phases [16]:

- Designing the systems to be used in the OEM's product.

- Supply chain integration to produce and deliver the requested systems to OEM.

- Provide services for the components for both OEM and supplier systems.

The IT solution to support PLM results from the integration between enterprise resource planning (ERP), product data management (PDM) and other related systems, such as computer aided design (CAD) and costumer relationship management (CRM) [17]. A critical aspect of PLM systems is their product information modeling architecture. In the literature, several representations of the product data are presented [18], [19]. The unified representation of the product knowledge can favor semantic interoperability of $\mathrm{CAD} / \mathrm{CAE} / \mathrm{CAM}$ systems at the conceptual level [20]. UML is currently used to support product models [2]. STEP and XML are used to obtain interoperability at the implementation level [22]. Sudarsan [23] propose a product information-modeling framework that aimed at support PLM 
information needs and intended to capture product data, design rationale, assembly, tolerance information, the evolution of products and product families.

However, product model is not the unique element in a PLM data models. Nowak [24] present architecture of a collaborative aided design framework integrating Product, Process and Organization models for engineering performance improvement. Danesi [25] propose the P4LM methodology which allows the management of Projects, Products, Processes, and Proceeds in collaborative design and that aims to allow the integration of information coming from different partners which are involved in a PLM application. This framework allows a topdown approach by defining functions in an abstraction level according to four modules (Project, Product, Proceed and Process).

In aim to get best integration of suppliers in the automotive design and manufacturing processes, Trappey [26] develops and implements an information platform called advanced production quality planning (APQP) hub. The information hub mainly provides a collaborative environment that enhancing the visibility of the supply chain operations and contributes in collecting and delivering APQP documents among both the OEM and all supply chain. This information platform applies the concept of modularized assembly and consists of five major functions: Categorized part library, project based collaborative design, real-time information exchange, on-line confirmation of modularized products, and on-line negotiation and ordering. Each one of the obvious functions is implemented according to an interactive process.

Our work deals with the integration of Product, Process, and Organization dimensions of a design project. Several models are developed to support, at the conceptual level, this integration.

\section{The Package model of the PLM approach}

At the conceptual level, our approach is based on the concept of working situation proposed in [27]. According to this model, each process and activity in a collaborative design project is considered as an interactional entity that refers to links between various entities of the situation. These entities may bring together different physical elements such as human resources and material resources (product, drawings, documents, CAD tools, planning tools, etc). It may bring together, also, other interactional entities (activities, processes, communities).

The nature of the contribution made by each entity to the interactions is formalized in this approach using the concept of specific role that is a systemic extension of the role proposed in the organization theory [28]. Five kinds of specific roles are distinguished:

- The "actor" role concerns every entity who/which participates directly in the interaction and who/which is responsible for the end result.

- The "customer" role brings together all the entities that are going to be receiving the end result of the interaction. 
- The "manager" role concerns every entity who/which regulates the functioning of an interaction.

- The "support" role includes every entity who/which give help in an interaction.

- The "object" role concerns every entity on whom/which the interaction acts.

Figure 3 describes the global package model structuring the PLM data. According to this model, the assembly tool (equipment) may be considered as a mediation artifact since it is simultaneously a support of the assembly aircraft project (that is performed in the OEM Assembly Workshop) and, the main object of the equipment project (that are realized by the new trade organization). Aircraft project plays the role of customer of the equipment project. The different needs of the equipment project are specified according to the different activities of the aircraft assembly process. Thus, Aircraft processes take also the role of customer in the equipment processes.

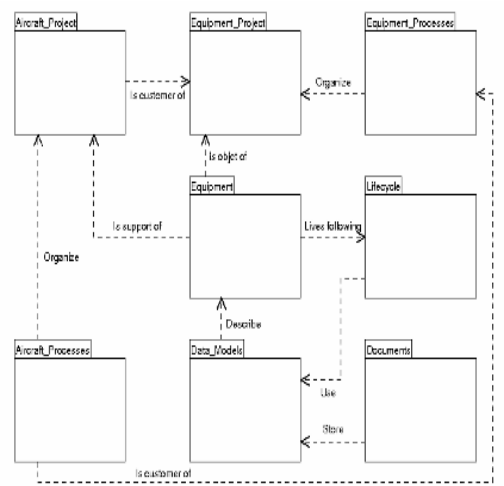

Figure 3 The package model structuring our PLM approach.

The processes packages (of aircraft and equipment) group various processes that organize the functioning of related projects. For example, design and fabrication processes are the principal processes of the equipment project, its play the role "actor". The process data concerns both the assembly process of aircraft parts and design process of the equipment. Saved information is used to recognize the activities evolution of each partner (new requirement of the OEM, new kind of assembly tools proposed by suppliers ...).

The data model package organizes, according to various sub-models, the equipment's information that are produced and manipulated during different stages of the whole equipment lifecycle. The detailed data are stored in different documents represented by "documents package". For example, the structural model contains information about the physical composition of the equipment. The detailed structure is stored in $\mathrm{CAO}$ documents. 


\section{The project view}

We consider the concept of project as a form of operational interaction including a set of processes in order to obtain specific goals. The project structure consists of a systemic decomposition into different sub-projects regarding to the product complexity.

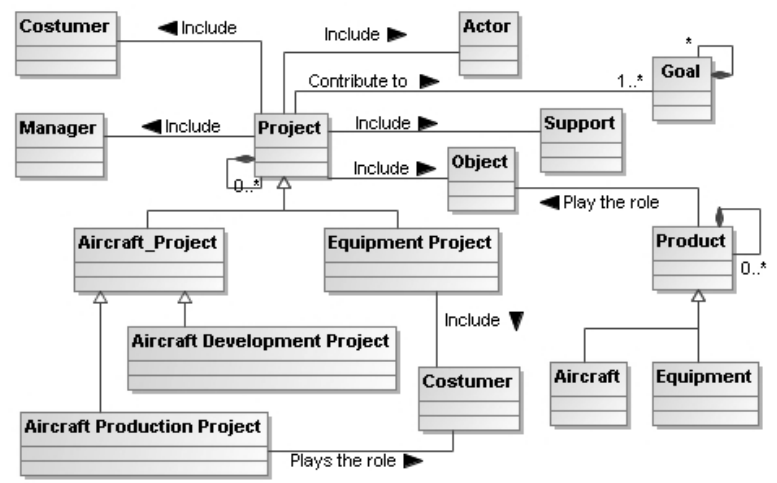

Figure 4 The project view.

Figure 4 shows the Meta model of the project structure, the project is considered as an interactional entity according to the situation concept (cf. section 2). Each project contributes to one or several goals. The class "goals" make dependence between the project view, the process view and the task view.

The project Meta model presents the contribution of different elements similarly at the organizational level (organization of different human resources and communities) and at the operational level (organization of different processes). The contribution of all project elements is presented by an instantiation of: \{the class entity, the class role (replaced by a specific subclass) and interactional entity (in this case project)\}. For instance, the Aircraft project is associated to the Equipment project by mean of the "Customer" class.

The main idea is that both the aircraft design project and equipment design project are described under the same main project reference. When a manufacturing order of an assembly tool is submitted, a new sub project for this need is created. All aircraft sub-project that are concerned by this equipment are related to the above project in the global situation framework. For this use case, three specific roles where to be considered:

- The aircraft R\&D takes the role of actor in the aircraft design process and the indirect "customer" in the equipment design process (send the original needs through the production department). We note this entity "Aircraft_R\&D".

- The production department takes the role of support in the aircraft design process; it performs different assembly operations. At the same time, it takes the 
role of "customer" in the equipment design process (define the assembly procedure and assembly tool functions). We note this entity "Aircraft_Prod".

- The R\&D service of the new business partnership takes the role actor of the equipment design process. We note this entity "Equipment_R\&D".

- The manufacturing service of the new business partnership takes the role support of the equipment design process. This entity is noted "Equipment_Prod".

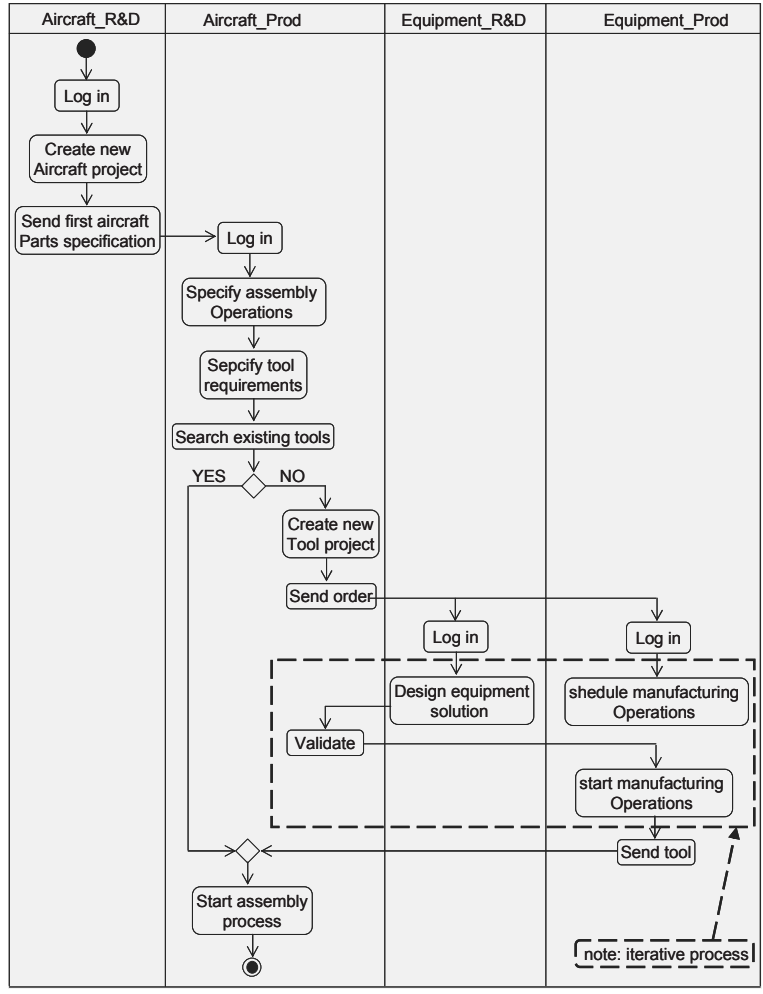

Figure 5 Scenario of creating new equipment project.

Several modeling tools are used to describe process achievement (IDEF, GRAI, UML, etc.). UML formalism give more advantages since it gives possibility to represent the static view (class diagram, object diagram) and the dynamic view (activity diagram, state diagram, etc.) In our approach, we used the Activity diagram of UML formalism as it is shown in the previous figure (figure 5) to describe the interaction process during the creation of a new project. At the beginning, Aircraft $R \& D$ creates a new project and sends initial specifications to the production department. It defines the different operations of the assembly process and specifies the functions of the assembly tool to be realized. After, it searches in the furniture warehouse a tool which satisfies these functions. If no tool is founded, pro- 
duction department creates new equipment sub project and sends information to the supplier network (equipment R\&D and manufacturing).

In fact, the real process is established in concurrent way. When, the equipment R\&D starts the design process, manufacturing service is simultaneously schedules the manufacturing operations and researches the available technological solutions. Thanks to the collaborative system, the specification and manufacturing of the assembly tool is performed progressively and co-jointly by different partners according to the global scenario.

When a modification in the aircraft structure is occurred, the system informs the members of the business partnership and sends him the new requirement to consider in the specification of the related assembly tool. Figure 6 presents the interaction process for this case.

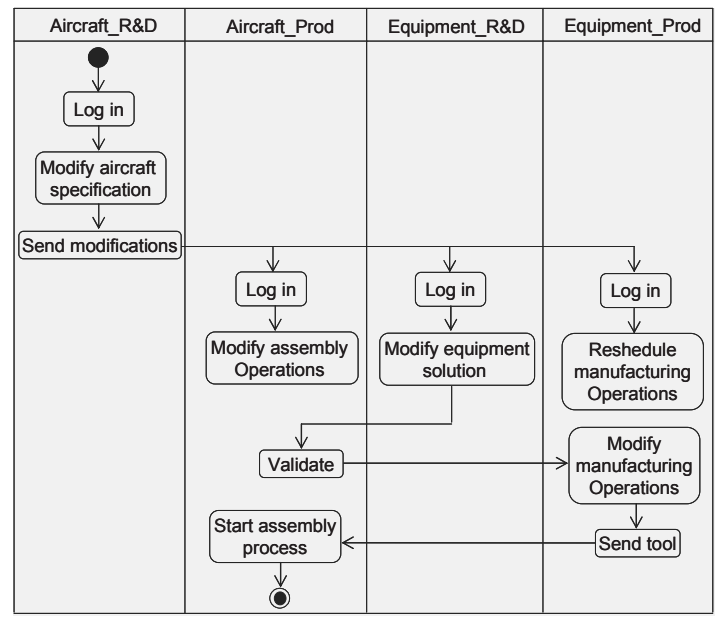

Figure 6 Scenario of modifying requirement.

\section{Conclusions}

In this paper, we have proposed a modeling framework to support, at the conceptual level, a new PLM approach to improve information sharing in collaborative design, and then to enhance the integration of supplier in the design and manufacturing processes. The final goals of the project is to reduce costs and time to market of the assembly tools, and consequently thus of the aircraft product.

The new business partnership implies to establish new collaboration strategy between OEM and supplier. Other benefits can be obtained from this framework by monitoring the evolution of collective work and facilitating its coordination. 
The developed framework deals with the integration of Product, Process and Organization dimensions of a design project, and, in future works, the corresponding extension of $\mathrm{CAD} / \mathrm{CAM}$ and PDM existing tools. The proposed Product model gives the structure of the product data base. It uses a generic semantic that can favor, in our sense, the conceptual interoperability between different product data coming from different partners.

Although our work is developed initially to resolve a particular problem in a special firm of the aeronautic industry, the use of a modeling framework based on the generic concepts of entities and interactions in the working situation may gives more interests.

In this contribution, one specific dimension has been developed, related to the PLM platform, to support the shift from a sequential to an interactionnist development process. Face to the complexity of such a change, success will not only rely on this support dimension. This PLM platform will have to be considered in a more global system/organisation, to take into account the entanglement of technology, market and usage dimensions. At an operational level, this integrated approach will enhance the chances of success and at a more analytic level, it will allow to precise the conditions of application and transposition in other contexts.

Further research work will be performed to improve and validate these different issues. A prototype is under development and is being tested thanks to our industrial case study.

\section{References}

1. Kline S.J., Rosenberg N.: An overview of innovation. In: Landau R., Rosenberg, N. (eds) The positive sum strategy. pp. 275-306 (1986).

2. Nishiguchi T., Ikeda M.: Suppliers' innovation: undestated aspects of japanese industrial sourcing. In: Nishiguchi, (Ed.), Managing Product Development. pp. 206-232, Oxford University Press (1996).

3. Chung S., Kim G.M.: Performance effect of partnership between manufacturers and suppliers for new product development: the supplier's standpoint. Research Policy, vol. 32, pp. 587-603 (2003).

4. Foss N.J.: Theories of the firm: contractual and competence perspective. Journal of evolutionary economics, vol. 3, pp. 127-144 (1993).

5. Ben Mahmoud-Jouni S., Calvi R.: Les coopérations interentreprises dans les projets de développement. In: Garel (ed.): Faire de la recherche en management de projet, Vuibert (2004).

6. Calvi R.: Le rôle des services achats dans le développement des produits nouveaux: une approche organisationnelle. Revue Finance, Contrôle, Stratégie, vol. 3(2), pp. 31-55 (2000).

7. Nooteboom, B.: Learning and innovation in organizations and economies, Oxford (2000).

8. Hamel, G., Prahalad, C.K.: Strategy as Stretch and Leverage. Research-Technology Management, vol. 36(6), pp. 40-47 (1993).

9. Ouchi, W.: Markets, bureaucracies, Administrative Science Quaterly, vol. 25(3), pp. 129$141(1980)$.

10. Huet, F.: Capacités d'innovation et coopération de PME: des effets auto-renforçants. Revue Internationale des PME, vol. 19(1), pp. 95-101 (2006). 
11. Adler, P.S.: Market hierarchy and trust. The knowledege Economy and the future of capitalism. Organization Science. vol. 12( 2), pp. 215-234 (2001).

12. Saaksvuori, A., Immonen, A.: Product Lifecycle Management. Springer, Berlin (2004).

13. Jun, H., Kiritsis D., Xirouchaki, P.: Research issues on closed-loop PLM. Computer in Industry, vol. 57, pp. 855-868 (2007).

14. Gomes, J.O., Vallejos, R.V.: Applying a benchmarking method to organize the product lifecycle management for aeronautic suppliers. Product Lifecycle Management, vol. 3 (2007).

15. Tang, D., Qian, X.: Product lifecycle management for automotive development focusing on supplier integration. Computer in Industry, vol. 59, pp. 288-295 (2008).

16. Schilli, B., Dai, F.: Collaborative life cycle management between suppliers and OEM, Computers in Industry, vol. 57, pp. 725-731 (2006).

17. Schuh, G., Rozenfeld, H., Assmus, D., Zancul, E.: Process oriented framework to support PLM implementation. Computers in Industry, vol. 59, pp. 210-218 (2008).

18. Terzi, S., Cassina, J., Panetto, H.: Development of a metamodel to foster interoperability along the product lifecycle traceability. International conference on Interoperability of Enterprise Software and Applications. IFIP-ACM/SIGAPP INTEROP. Geneva, Switzerland (2005).

19. MOKA.: Managing engineering knowledge: methodology for knowledge based engineering applications, Wiley (2001).

20. Szykman, S., Fenvesa, S.J., Keirouzb, W., Shooter, B.: A foundation for interoperability in next-generation product development systems. Computer-Aided Design, vol. 33, pp. 545559 (2001).

21. Eynard, B., Gallet, T., Nowak, P., Roucoules, L.: UML based specifications of PDM product structure and workflow. Computers in Industry, vol. 3, pp. 301-316 (2004).

22. Fenves, S.J., Foufou, S., Bock, C., Sudarsan, R., Bouillon N., Sriram R.D.: CPM2: A revised core product model for representing design information. National Institute of Standards and Technology, NISTIR7185, USA (2004).

23. Sudarsan, R., Fenves, S.J., Sriram, R.D., Wang, F.: A product information modeling framework for product lifecycle management. Computer-Aided Design, vol. 37, pp. 1399$1411(2005)$.

24. Nowak, P., Rose, B., Saint-Marc, L., Callot, M., Eynard, B., Gzara L., Lombard, M.: Towards a design process model enabling the integration of product, process and organization. $5^{\text {th }}$ International Conference on Integrated design and Manufacturing in Mechanical Engineering IDMME, University of Bath, UK (2004).

25. Danesi, F., Gardan, F., Gardan, Y., Reimeringer M.: P4LM: A methodology for product lifecycle management. Computers in Industry vol. 59, pp. 304-317 (2008).

26. Trappey, A.J., Hsio, D.: Applying collaborative design and modularized assembly for automotive ODM supply chain integration. Computers in Industry, vol. 59, pp. 277-287 (2008).

27. Belkadi, F., Bonjour, E., Dulmet, M.: Modelling Framework of a Traceability System to Improve Knowledge Sharing and Collaborative Design. CSCW in Design. Lecture Notes in Computer Science, vol. 3865 (2006).

28. Uschold, M., King, M., Moralee, S., Zorgios Y.: The Enterprise Ontology. The Knowledge Engineering Review, vol. 13, pp. 1-12 (1998). 